\title{
Keanekaragaman Jenis Mangrove di Pantai Kapeta dan Pantai Tanaki, Kecamatan Siau Barat Selatan, Kabupaten Sitaro - Sulawesi Utara (Mangrove Diversity of Kapeta Beach and Tanaki Beach, South West Siau District, Sitaro Regency - North Sulawesi)
}

\author{
Ivandri Viktor Kirauhe ${ }^{1)}$ Ratna Siahaan ${ }^{1)^{*}}$ Johanis Julian Pelealu') \\ 1) Jurusan Biologi Fakultas MIPA Universitas Sam Ratulangi, 95115 \\ ${ }^{\star}$ Email korespondensi: ratna245_siahaan@yahoo.com
}

Diterima 23 Januari 2016, diterima untuk dipublikasikan 4 Februari 2016

\begin{abstract}
Abstrak
Penelitian tentang keanekaragaman mangrove berdasarkan fungsi dan manfaat mangrove di Pulau Siau telah dilakukan untuk menganalisis keanekaragaman jenis vegetasi mangrove di Pantai Kapeta dan Pantai Tanaki, Kecamatan Siau Barat Selatan, Kabupaten Sitaro, Provinsi Sulawesi Utara. Metode garis berpetak berselang digunakan untuk memperoleh kekayaan dan kelimpahan jenis vegetasi. Garis transek diletakkan secara vertikal dari laut ke daratan sebanyak 3 jalur di tiap stasiun dengan jarak antar jalur sekitar $300 \mathrm{~m}$. Data dianalisis secara deskriptif. Indeks keanekaragaman jenis diketahui berdasarkan Indeks Shannon Wienner $\left(H^{\prime}\right)$. Pantai Kapeta dan Tanaki memiliki kekayaan jenis mangrove sebanyak 10 jenis dari 9 suku dan kelimpahan jenis sebesar 657 individu. Jenis mangrove yang ditemukan di Kecamatan Siau Barat Selatan yaitu Bruguiera gymnorrhiza, Sonneratia alba, Rhizophora apiculata, Nypa fruticans, Croton oblongus, Ficus, Heritiera littoralis, Intsia bijuga, Ixora talaudensis dan Terminalia catappa. Keanekaragaman jenis mangrove di wilayah penelitian Kecamatan Siau Barat Selatan tergolong rendah dengan indeks $H^{\prime}$ sebesar 0,775 yang lebih rendah dari 1. Keanekaragaman mangrove di Pantai Kapeta dan Tanaki juga rendah dengan indeks berturut-turut yaitu 0,654 dan 0,880.

Kata Kunci: keanekaragaman mangrove, Pantai Kapeta, Pantai Tanaki, Pulau Siau.
\end{abstract}

\begin{abstract}
The study on the diversity of mangrove on Siau Island based on the its functions and benefits was conducted to analyze the diversity of mangrove vegetation in Kapeta and Tanaki Beach, District of South West Siau, Sitaro Regency, North Sulawesi. The quadrate line transect method was used to obtain data of species richness and abundance. Three line transects were installed vertically from sea margin to land at each station. Line spaces were $300 \mathrm{~m}$. Data were analyzed descriptively. Biodiversity index of mangrove was based on Shannon - Wienner index ( $\left.H^{\prime}\right)$. Kapeta Beach and Tanaki Beach had species richness and abundance respectively i.e. 10 species of 9 familes and 657 individu. The mangrove found in South West Siau District i.e. Bruguiera gymnorrhiza, Sonneratia alba, Rhizophora apiculata, Nypa fruticans, Croton oblongus, Ficus, Heritiera littoralis, Intsia bijuga, Ixora talaudensis and Terminalia catappa. Mangrove diversity in the study area was low $\left(H^{\prime}\right.$ index $\left.=0.775\right)$. The diversity of mangrove in Kapeta Beach and Tanaki Beach were also low, i.e. 0.654 and 0.880 respectively.

Keywords: mangrove diversity, Kapeta Beach, Tanaki Beach, Siau Island.
\end{abstract}




\section{PENDAHULUAN}

Indonesia merupakan negara kepulauan yang memiliki hutan mangrove terluas di dunia (Onrizal 2010). Hutan mangrove umumnya dapat ditemukan di seluruh pantai Indonesia tepatnya pada lokasi yang mengalami pasang surut serta pada aliran sungai yang terdapat di sepanjang pesisir berlumpur (Bengen 2000).

Ekosistem mangrove merupakan sumber daya alam yang mudah terganggu sebab mudah dijangkau masyarakat. Hal ini menyebabkan ekosistem mangrove mengalami kerusakan yang berlangsung cepat (Ningsih 2008). Pembangunan di wilayah pesisir untuk berbagai kebutuhan seperti industri, pusat pembangkit listrik, lokasi rekreasi, permukiman, dan pertambakan menimbulkan degradasi mangrove (Susanto et al. 2013). Degradasi ekosistem mangrove akan berdampak pada penyusutan luas mangrove yang berakibat pada penurunan hilangnya keanekaragaman hayati (Prianto et al. 2006). Mangrove merupakan ekosistem yang unik dan rawan karena ekosistem mangrove memiliki fungsi ekologis dan manfaat ekonomis bagi manusia dan organisme lainnya baik secara langsung maupun tidak langsung (Susanto et al. 2013). Degradasi mangrove akan berdampak pada penurunan fungsi ekologis dan manfaat ekonomis tersebut.

Salah satu daerah di Sulawesi Utara yang masih memiliki hutan mangrove yaitu Kecamatan Siau Barat Selatan, Kabupaten Sitaro. Pulau Siau termsuk pulau kecil berukuran 160,02 $\mathrm{km}^{2}$ (Bapedda Sitaro 2015). Upaya rehabilitasi mangrove telah dilakukan Kantor Lingkungan Hidup Kabupaten Sitaro di Kecamatan Siau Barat Selatan, Kabupaten Sitaro pada tahun 2013. Jenis mangrove yang ditanam yaitu Rhizophora apiculata, Bruguiera gymnorrhiza dan Ceriops tagal. Kegiatan ini bertujuan mempertahankan mangrove yang ada di sepanjang pesisir Kecamatan Siau Barat Selatan. Tujuan akhir rehabilitasi ini untuk mempertahankan fungsi ekologis mangrove untuk mencegah abrasi sehingga garis pantai dapat dipertahankan. Upaya penanaman kembali ini belum berhasil disebabkan ombak besar di awal tahun 2014 sehigga banyak vegetasi mangrove yang hilang terbawa ombak.

Alih fungsi mangrove menjadi lahan untuk permukiman dan rekreasi telah menyebabkan perubahan mangrove di Kecamatan Siau Barat Selatan, Kabupaten Sitaro. Alih fungsi ini telah menyebabkan kerusakan vegetasi mangrove yang akan menurunkan fungsi ekologis mangrove tersebut. Kekayaan jenis mangrove di wilayah ini belum diketahui sehingga penelitian mengenai berapa banyak jenis-jenis vegetasi penyusun mangrove di wilayah ini perlu diteliti. Data kekayaan jenis vegetasi mangrove ini dapat menjadi data base keanekaragaman hayati vegetasi mangrove di Pulau Siau Barat Selatan. Data ini dapat dimanfaatkan oleh pemerintah setempat sebagai acuan untuk menentukan kebijakan pengelolaan mangrove di wilayah ini antara lain penanaman mangrove untuk mencegah abrasi dan mempertahankan keanekaragaman mangrove.

\section{METODE}

Penelitian ini dilaksanakan pada Juni - September 2015 di Pantai Kapeta dan Pantai Tanaki, Kecamatan Siau Barat Selatan, Kabupaten Sitaro, Sulawesi Utara. Lokasi penelitian ditetapkan dengan metode purposive dengan mempertimbangkan aksesibilitas dan keterwakilan mangrove. Lokasi penelitian terletak di 
Pantai Kapeta pada titik-titik koordinat yaitu 02³8'17,42" LU - 02॰38'21,04 LU dan $\quad 125^{\circ} 23^{\prime} 49,27^{\prime \prime} B T$

$125^{\circ} 24^{\prime} 01,62 " B T$. Lokasi penelitian di Pantai Tanaki pada titik-titik koordinat yaitu $02^{\circ} 38^{\prime} 08,72 " \mathrm{LU}-02^{\circ} 38^{\prime} 11,30 \mathrm{LU}$ dan $125^{\circ} 24^{\prime} 23,75^{\prime \prime} B \mathrm{~T}$

$125^{\circ} 24^{\prime} 41,63 " B T$ (Gambar 1). Alat dan bahan yang digunakan diantaranya kamera digital, GPS, tali rafia, meteran, oven, peta kawasan, patok, sasak, kantung plastik, gunting dan alkohol $70 \%$.

Penempatan plot ditentukan berdasarkan metode garis berpetak berseling (Kusmana 1997 dalam Indriyanto 2006). Jumlah jalur di Pantai Kapeta dan Tanaki sebanyak 6 jalur dengan jarak antar jalur sekitar $300 \mathrm{~m}$. Transek dibentangkan secara vertikal di area mangrove mulai dari tepi mangrove berbatasan dengan laut hingga tepi mangrove berbatasan dengan daratan. Petak kuadarat ditempatkan secara berseling di tiap garis transek dengan jarak antar petak kuadarat yaitu $30 \mathrm{~m}$. Jumlah petak kuadrat yang diletakkan di garis transek sebanyak 3 petak kuadrat.

Data keanekaragaman jenis mangrove diketahui dengan menggunakan Indeks Keanekaragaman (H') Shannon Wienner. Data ini dianalisis secara deskriptif. Adapun rumus Indeks keanekaragaman jenis Shannon -
Wienner (Maguran 2004) sebagai berikut:

Keterangan :

$$
\mathrm{H}^{\prime}=-\sum \mathrm{p}_{\mathrm{i}} \ln \mathrm{p}_{\mathrm{i}}
$$

$\mathrm{H}^{\prime}$ : Indeks keanekaragaman

Shannon - Wienner

$\mathrm{p}_{\mathrm{i}} \quad$ : kelimpahan dari jenis ke-i per

kelimpahan total $\left(\mathrm{n}_{\mathrm{i}} / \mathrm{N}\right)$

$\mathrm{N}$ : kelimpahan total jenis

\section{HASIL DAN PEMBAHASAN}

Luas Pulau Siau yaitu 160,02 $\mathrm{km}^{2}$ dengan topografi berbukit-bukit. Luas Kecamatan Siau Barat Selatan ialah $15,10 \mathrm{~km}^{2}$ yang terdiri dari 7 Desa (Bappeda Sitaro, 2015). Kecamatan Siau Barat Selatan berbatasan dengan Kecamatan Siau Barat di sebelah utara, dengan Kecamatan Siau Barat di bagian timur, dengan Kecamatan Siau Timur di bagian selatan dan dengan laut Sulawesi di bagian barat (BPS Sitaro 2014).

Ekosistem mangrove di Kecamatan Siau Barat Selatan sekarang sudah dijadikan kawasan konservasi lokal (KLH Sitaro 2015). Mangrove di wilayah ini sebagian telah rusak akibat abrasi pantai. Mangrove di Pantai Kapeta dan Pantai Tanaki sangat dekat dengan jalan raya sehingga masyarakat dengan mudah mengubah mangrove menjadi lahan permukiman. 


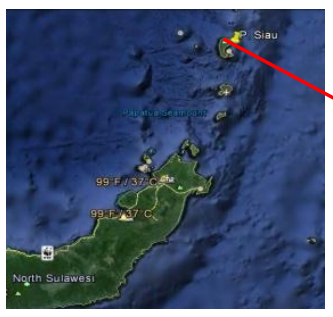

Pulau Siau, Sulawesi Utara

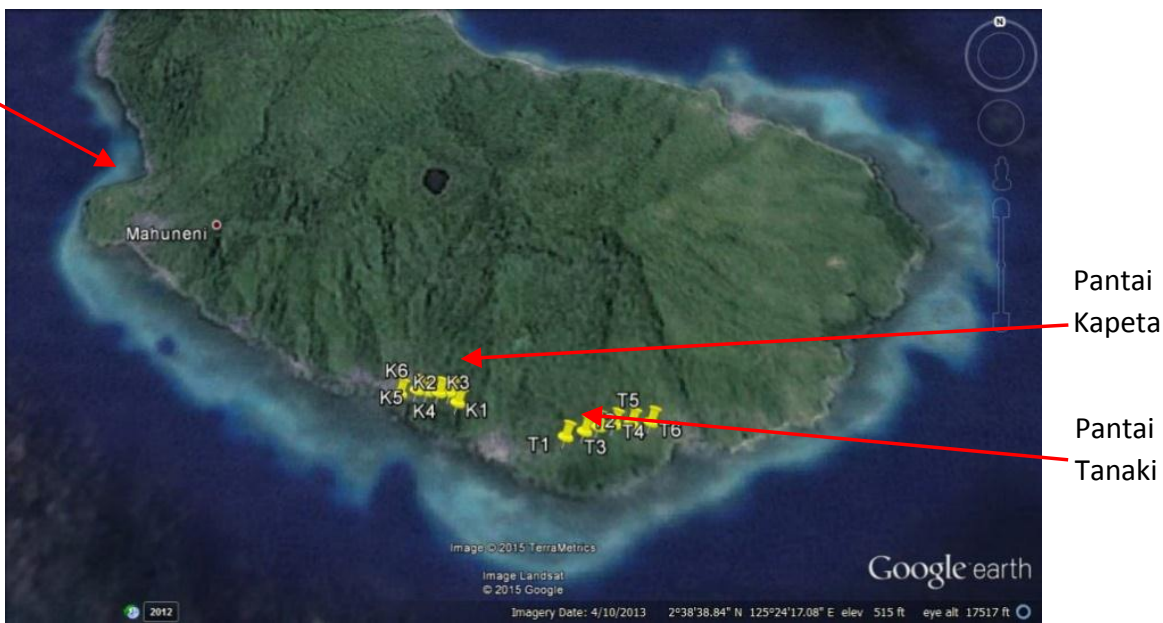

Gambar 1. Lokasi Penelitian
Mangrove yang ditemukan di Pantai Kapeta dan Pantai Tanaki sebanyak sepuluh (10) jenis yang termasuk ke dalam sembilan (9) suku. Kelimpahan individu tertinggi dimiliki oleh jenis Bruguiera gymnorhiza (325 individu) dan terendah dimiliki oleh Intsia bijuga, Ixora talaudensis, Ficus sp., Heritiera littoralis, Mangifera indica dan Terminalia catappa masingmasing sebanyak satu (1) individu (Tabel 1).

Mangrove tersebar dari tepian laut hingga berbatasan degan daratan. Mangrove mayor (true mangrove) tersebar di area pasang surut yaitu Bruguiera gymnorhiza, Sonneratia alba, Rhizophora apiculata dan Nypa fruticans. Mangrove minor hanya menempati tepian habitat yaitu Intsia bijuga, Ixora talaudensis, Ficus sp. Heritiera littoralis, dan Croton oblongus. Mangrove asosiasi (associated mangrove) yang berinteraksi dengan mangrove mayor dan minor yaitu Terminalia catappa. Distribusi jenis mangrove tampak dari bagian depan yang menghadap laut ke bagian belakang yang menghadap daratan. Jenis Sonneratia alba tersebar di bagian depan dari Pantai Kapeta dan Tanaki. Mangrove Rhizophora apiculata dan Bruguiera gymnorrhiza ditemukan melimpah di bagian tengah. Mangrove mayor Nypa fruticans terletak di bagian belakang yang dekat dengan sungai. Seluruh mangrove minor dan asosiasi menempati habitat di bagian belakang pantai yang berbatasan dengan daratan. Hal senada juga dikatakan oleh Bengen (2000) bahwa zonasi mangrove secara berurutan dari depan ke belakang yaitu Sonneratia, Rhizophora, Bruguiera dan Nypa fruticans.

Kekayaan jenis mangrove sejati di Pulau Sulawesi dan Indonesia tercatat sebanyak 29 jenis (Kordi 2012) dan 43 jenis (Noor et al. 1999). Kekayaan jenis mangrove mayor yang ditemukan di Pantai Kapeta dan Tanaki termasuk rendah yaitu hanya 5 jenis atau $17,24 \%$ dari mangrove mayor di Pulau Sulawesi. Distribusi mangrove dipengaruhi oleh berbagai faktor yaitu iklim, salinitas, fluktusi pasang surut, sedimen dan energi ombak (McKee 1996). 
Tabel 1. Kekayaan (S), Kelimpahan (N) dan Indeks Keanekaragaman Jenis Shannon (H') Mangrove di Pantai Kapeta dan Pantai Tanaki, Kecamatan Siau Barat Selatan

\begin{tabular}{|c|c|c|c|c|c|}
\hline \multirow{2}{*}{ No } & \multirow{2}{*}{ Jenis } & \multirow{2}{*}{ Suku } & \multicolumn{2}{|c|}{ Lokasi } & \multirow{2}{*}{$\mathrm{K}$ dan $\mathrm{T}$} \\
\hline & & & Kapeta & Tanaki & \\
\hline 1 & Bruguiera gymnorhiza & Rhizophoraceae & 325 & 200 & 525 \\
\hline 2 & Sonneratia alba & Lythraceae & 32 & 25 & 57 \\
\hline 3 & Rhizophora apiculata & Rhizophoraceae & 11 & 31 & 42 \\
\hline 4 & Nypa fruticans & Arecaceae & 15 & 7 & 22 \\
\hline 5 & Croton oblongus & Euphorbiaceae & - & 5 & 5 \\
\hline 6 & Ficus sp. & Moraceae & 2 & - & 2 \\
\hline 7 & Intsia bijuga & Fabaceae & - & 1 & 1 \\
\hline 8 & Ixora talaudensis & Rubiaceae & 1 & - & 1 \\
\hline 9 & Heritiera littoralis & Malvaceae & 1 & - & 1 \\
\hline 10 & Terminalia catappa & Combretaceae & 1 & - & 1 \\
\hline & $\mathrm{N}$ (individu) & & 388 & 269 & 657 \\
\hline & S & & 8 & 6 & 10 \\
\hline & $H^{\prime}$ & & 0,654 & 0,880 & 0,775 \\
\hline
\end{tabular}

Keterangan: K: Pantai Kapeta ; T: Pantai Tanaki

Kekayan dan kelimpahan jenis mangrove yang ditemukan di Pantai Kapeta dan Tanaki berturut-turut yaitu 8 jenis; 388 individu dan 6 jenis; 269 individu. Nilaiindeks keanekaragaman (H') mangrove Pantai Kapeta, Pantai Tanaki dan di kedua wilayah penelitian berturut-turut yaitu 0,$654 ; 0,880$ dan 0,775 (Tabel 1). Keanekaragaman vegetasi mangrove di wilayah penelitian Kecamatan Siau Barat Selatan termasuk rendah berdasarkan kriteria Fachrul (2007) yaitu nilai H' < 1 termasuk rendah. Keanekaragaman vegetasi mangrove yang rendah tersebut disebabkan jenis Bruguiera gymnorhiza sangat melimpah di kedua lokasi penelitian. Kenekaragaman jenis dipengaruhi oleh dua faktor yaitu kekayan jenis (S) dan kelimpahan jenis (N). Komunitas memiliki keanekaragaman tinggi jika kedua faktor tersebut tinggi (Maguran 2004). Kordi (2012) menyebutkan bahwa komunitas dikatakan memiliki keanekaragaman jenis yang rendah apabila komunitas itu dibentuk oleh sedikit jenis dan jika hanya ada sedikit jenis yang dominan.

\section{KESIMPULAN}

Pantai Kapeta dan Tanaki, Kecamatan Siau Barat Selatan memiliki kekayaan jenis mangrove sebanyak 10 jenis dari 9 suku dan kelimpahan jenis sebesar 657 individu. Keanekaragaman mangrove di Pantai Kapeta, Pantai Tanaki dan di kedua wilayah penelitian tergolong rendah dengan indeks $\mathrm{H}^{\prime}$ berturut-turut yaitu 0,$654 ; 0,880$ dan 0,775 . Distribusi mangrove dari laut ke daratan yaitu Sonneratia alba yang berbatasan langsung dengan laut dilanjutkan ke arah daratan sebagai berikut , Rhizophora apiculata, Bruguiera gymnorhiza , dan Nypa fruticans.. Mangrove mayor yang ditemukan yaitu Bruguiera gymnorhiza, Sonneratia alba, Rhizophora apiculata dan Nypa fruticans. Mangrove minor yaitu Heritiera littoralis, Intsia bijuga, Ixora talaudensis, Ficus sp. dan Croton oblongus. Mayor asosiasi yaitu Terminalia catappa. 
6 JURNAL BIOSLOGOS, FEBRUARI 2016, VOL. 6 NOMOR 1

DAFTAR PUSTAKA

Bappeda Sitaro (2015) Peta administrasi Kecamatan Siau Barat Selatan. Bappeda Sitaro. Ondong

Bengen DG (2000) Pedoman teknis: pengenalan dan pengelolaan ekosistem mangrove. PKSP Lautan IPB. Bogor

BPS Sitaro (2014) Keadaan geografis Kecamatan Siau Barat Selatan. Siau

Fachrul MF (2007) Metode sampling bioekologi. Bumi Aksara. Jakarta

Indriyanto (2006) Ekologi hutan. Bumi Aksara.Jakarta

KLH Sitaro (2015) Pengadaan dan penanaman bibit tanaman bakau. Siau Tagulandang Biaro. Ondong

Kordi MG (2012) Ekosistem mangrove: potensi, fungsi, dan pengelolaan. PT. Rineka Cipta. Jakarta

Maguran AE (2004) Measuring biological diversity. Blackwell Science Ltd. Malden

McKee KL (1996) Mangrove ecosystems: definitions, distribution, zonation, forest structure, trophic structure, and ecological significance. Dalam: Feller IC, Sitnik M (eds). Mangrove ecology: a manual for a field course - a field manual focused on the biocomplexity on mangrove ecosystems. Smithsonian Institution. Washington DC

Ningsih SS (2008) Inventarisasi hutan mangrove sebagai bagian dari upaya pengelolaan wilayah pesisir Kabupaten Deli Serdang. Tesis. Universitas Sumatera Utara. Medan

Noor YR, Khazali M, Suryadipura INN (1999) Panduan pengenalan mangrove di Indonesia. PHKA/WI-IP. Bogor

Onrizal (2010) Perubahan tutupan hutan mangrove di Pantai Timur Sumatera Utara Periode 1977-2006. Biologi Indonesia 6 (2):163-172

Prianto E, Jhonnerie R, Firdaus R, Hidayat T, Miswadi (2006) Keanekaragaman hayati dan struktur ekologi mangrove dewasa di Kawasan Pesisir Kota Dumai-Propinsi Riau. Biodiversitas 7 (4):327-332 